\title{
La emblemática y el pensamiento económico español de finales del siglo XVI y principios del XVII
}

\author{
ROGELIO FERNÁNDEZ DELGADO \\ Universidad Rey Juan Carlos, Facultad de Ciencias Jurídicas y Sociales, Campus de Vicálvaro, Paseo \\ de los Artilleros, s/n, 28032 Madrid, España.E-mail: rogelio.fernandez@urjc.es
}

\begin{abstract}
RESUMEN
En 1531 el jurista italiano Andrea Alciato (1492-1550) publicó la obra Emblematum liber que tuvo una gran influencia en toda la Europa de la Edad Moderna. El trabajo de Alciato estaba compuesto por una antología de textos poéticos que estaban ilustrados y que a su vez contenían cada uno de ellos un título o lema. Así, por medio de la ilustración y el lema se pretendía facilitar la comprensión o interpretación del texto por parte del lector. Esta obra es considerada el punto de partida de la emblemática que más tarde dio lugar al género literario de la emblemática.

La obra de Alciato animó o a muchos autores a seguir el camino de los emblemas. La correspondencia entre el título -inscriptio-, la imagen -pictura-, con un texto explicativo -subscriptio o epigrama- dio lugar a un género consolidado que se extendió por Europa. Pues bien el objetivo de este trabajo es presentar la influencia que la emblemática tuvo en el pensamiento económico español de finales del siglo XVI y principios del XVII, en concreto en las obras de Cristóbal Pérez de Herrera (1556-1620) y Diego Saavedra Fajardo (1584-1648).
\end{abstract}

Palabras clave: Emblemática, inflación, pobreza, impuestos, comercio.

\section{The Emblematic and Spanish Economic Thought of the Late Sixteenth and Early Seventeenth}

\begin{abstract}
In 1531 the Italian jurist Andrea Alciato (1492-1550) published Emblematum liber, a work that had a great influence on Europe. Alciato's work consisted of an anthology of poems that were illustrated, each of which had a title or theme. The purpose of the illustration and the title was intended to facilitate the understanding and interpretation of the text by the reader. Emblematum liber is considered the starting point of the emblematic which later gave rise to the emblematic literary genre.

Alciato's work encouraged many authors to follow the path of the emblems. The correspondence between the title (inscription), image (pictura), and explanatory text (subscriptio or epigrama) gave rise to a consolidated gender that spread rapidly throughout Europe. The purpose of this paper is to present the influence that emblematic had on Spanish economic thought of the late sixteenth and early seventeenth centuries, in particular on the works of Cristóbal Pérez de Herrera (1556-1620) and Diego Saavedra Fajardo (1584-1648).
\end{abstract}

Keywords: Emblems, Inflation, Poverty, Taxes, Commerce.

Clasificación JEL: B10, B11, Z11

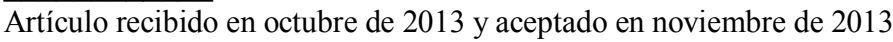

Artículo disponible en versión electrónica en la página www.revista-eea.net, ref. ə-32110 


\section{EL GÉNERO LITERARIO DE LA EMBLEMÁTICA}

La emblemática fue una manifestación cultural que se desarrolló en Europa y América durante los siglos XV al XVIII, aunque fue en el siglo XVI y sobre todo en el XVII cuando tuvo su máximo apogeo. Esta nueva forma de concebir la exposición se difundió en los llamados libros de emblemas, la fiesta pública, el teatro, los pasquines satíricos, los retratos, las portadas de libros, las marcas de impresor, los adornos de techos o paredes en las casas, palacios, conventos y navíos (López Poza, 2012: 38).

El origen de esta nueva manifestación cultural se encontraba en el emblema que era una representación simbólica que integraba dos artes, la pintura y la literatura. El emblema se colocaba al principio de los escritos con la intención de que la imagen facilitara la asimilación por parte del lector, del mensaje que quería transmitir el autor. Como afirma el profesor Maravall, el fin que perseguía el emblema era impresionar la voluntad, producir una acción directiva sobre el ánimo valiéndose de medios sensibles (Maravall, 1997: 52-53). Bien es cierto, y así hay que reconocerlo, que a lo largo de la historia la simbiosis entre la imagen y la palabra ha tenido un largo recorrido, pero son los estudiosos de la emblemática los que nos enseñan que fue en Europa a mediados del siglo XVI cuando se dieron condiciones especialmente fructíferas como para que dicha simbiosis adquiriera el rango de género literario.

Si el origen del género literario se encuentra en el emblema, la obra con la que inicia la andadura fue el Emblematum liber (1531) del jurisconsulto italiano Andrea Alciato (1492-1550). Antes de que el trabajo de Alciato fuera publicado y editado como el primer libro de emblemas, había realizado una composición de noventa y nueve epigramas o sentencias tituladas, que fueron las que sirvieron de base para el libro. Fue el diplomático alemán Conrad Peutinger (1465-1547) el que hizo llegar los epigramas a manos de un impresor que fue quien añadió los dibujos. El libro salió publicado en 1531 en Augsburgo con el título Emblematum liber. La obra tuvo un enorme éxito, se hicieron ciento setenta y cinco ediciones, y muy pronto fue imitada por otros autores y editada con abundantes comentarios convirtiéndose en un clásico (López Poza 1999: 31).

Cabe señalar que la obra de Alciato contribuyó a renovar la jurisprudencia tradicional sobre todo en la forma de exposición de los trabajos jurisprudenciales. Junto a Alciato, Guillermo Budeo (1468-1540) y Antonio de Nebrejia (1441-1522) forman parte de un humanismo jurista que contribuyó a relanzar una nueva concepción del Estado a mediados del siglo XVI (Touchard, 2000: 207). Andrea Alciato es considerado el primer autor que exportó los nuevos métodos del humanismo jurídico italiano a Francia estableciendo nuevas teorías sobre la soberanía popular (Skinner, 1986: 137). 
Esta renovación se caracterizó por una actitud crítica, apoyada en métodos históricos y filológicos, acerca de la autenticidad y fiabilidad de las fuentes que hasta el momento habían servido de fundamentado a la jurisprudencia tradicional (Fernández Delgado, 2006a: 82-83). Precisamente, mientras que el trabajo de los religiosos en el siglo XVI se reflejaba en voluminosos tratados de Derecho canónico De iustitia et iure, o en la reprobación de prácticas usurarias o cambios ilícitos de los Manuales de confesores (Reeder, 2003b: 729), el trabajo de los juristas y políticos de finales del siglo XVI y durante el XVII, pertenecientes en su mayor parte a esta nueva actitud crítica, lo van a hacer en monografías con sentido pragmático, redactadas para crear un estado de opinión que facilitara la introducción de las reformas políticas. Para el caso de España, y más concretamente en el ámbito del pensamiento económico esta forma de exposición va a tener continuidad. Así por ejemplo en teoría monetaria destaca a principios del siglo XVII el influyente tratado De monetae mutatione (1609) de Juan de Mariana, conocedor de Guillermo Budeo y Nebrija, y autor de una Historia de España. En este mismo sentido, y dentro de lo que van a ser las ideas económicas en el siglo XVIII, Gaspar Melchor de Jovellanos realizó un Informe sobre la ley agraria (1784) donde llevó a cabo un importante estudio histórico-jurídico que sirvió de base a las reformas de la agricultura española (Lalinde, 1983: 576).

Siguiendo esta nueva forma de concebir la exposición, el emblema adquirió especial protagonismo sobre todo por la facilidad con la que se incorporó a los trabajos, incluso, han llegado a ser considerados el caso extremo de la tendencia de la literatura a lo pictórico (Marvall, 1997, 56-57). Técnicamente el emblema está compuesto por tres partes: el título; la figura y el texto explicativo. El título, lema o mote, solía ser una sentencia aguda y en cierto modo enigmática, casi siempre en latín, que tenía por objetivo proporcionar pistas para entender el sentido de la imagen. Con relación a la figura, pictura, o cuerpo del emblema, se encontraba grabada o calcografiada, aunque también solía estar pintada o incluso bordada. En último lugar se encontraba el texto explicativo, epigrama o subscriptio, íntimamente relacionado con la figura y con el título. Con mucha frecuencia esta explicación solía hacerse en verso utilizando epigramas latinos o en lengua vernácula (López Poza 1999: 32-33).

Como se puede observar en el siguiente emblema, a modo de ejemplo, y que se corresponde con el número veinticinco de la edición de 1549 del Emblematum liber de Alciato, encima de un túmulo se encuentra en posición yacente una figura de mujer. El sepulcro tiene grabados dos figuras de animales. Pues bien, como nos cuentan López Poza, y Fernández Vales (2013), el motivo representa la imagen de una mujer, una prostituta -Lais de Corinto- semidesnuda, muy delgada y avejentada que yace sobre un noble sarcófago en uno de cuyos laterales es visible el relieve de una leona sujetando a un carnero con una de sus patas delanteras. 
Figura 1

Emblema 25, Emblematum liber

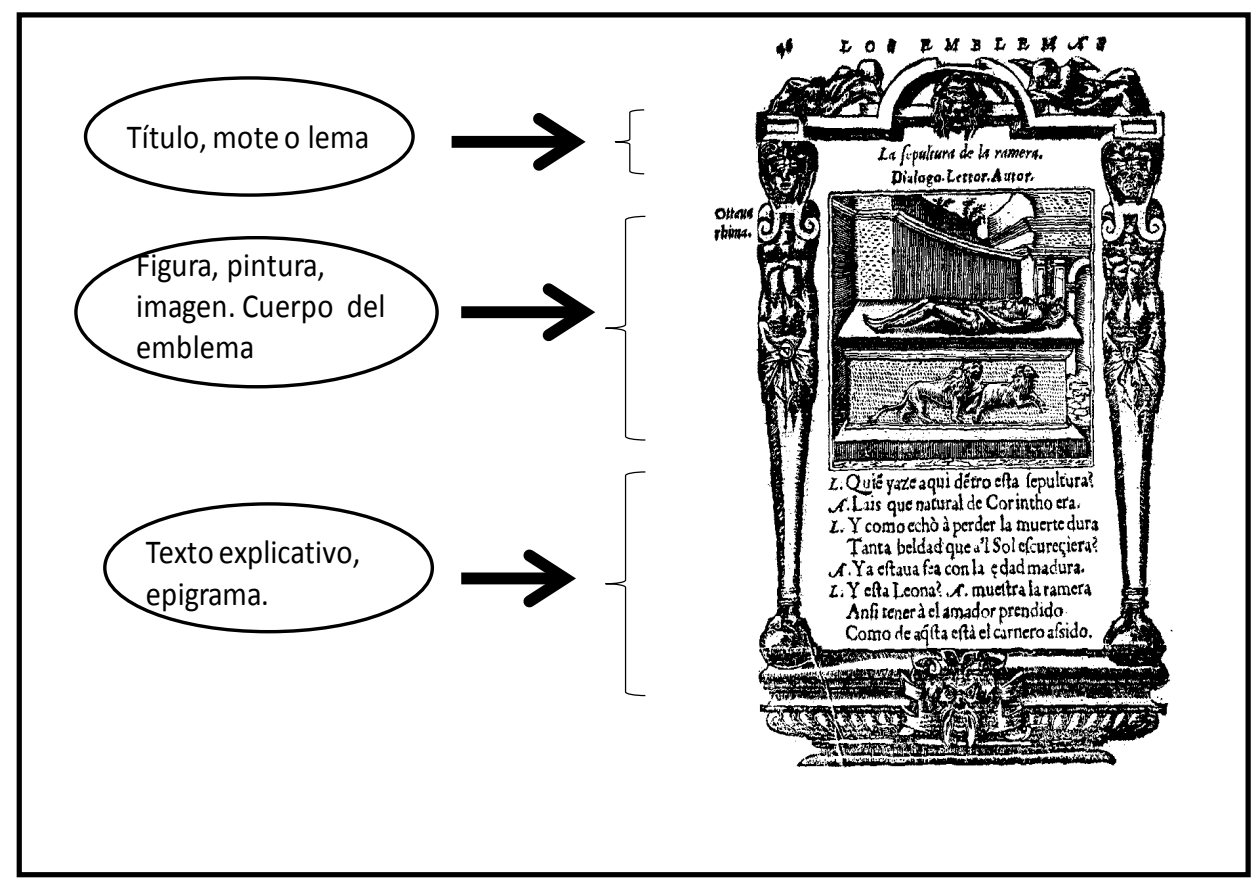

Fuente: Alciato, 1549.

El emblema tiene el siguiente epigrama:

L. ¿Quién yace aquí dentro esta sepultura?

A. Lais, que natural de Corinto era.I

L. ¿Y cómo echó a perder la muerte duralTanta beldad que al sol escureciera?

A. Ya estaba fea con la edad madura.।

L. ¿Y esta leona?

A. Muestra la rameralasí tener al amador prendidolcomo de aquésta está el carnero asido.

El significado del emblema es doble, por un lado muestra que la belleza no puede soportar el paso del tiempo y, por otro, nos enseña que los amantes se comportan como los carneros incautos que se dejan atrapar por la leona, en este caso, la prostituta (López Poza y Fernández Vales, 2013).

Hay que añadir que este género, cuya base se fundamentaba en el estilo sentencioso y conciso de Alciato, donde también se apelaba a resortes psicológicos, vino a constituir una preparación adecuada para el desarrollo de una línea de 
pensamiento político en España que cultivará directamente el Tacitismo (Maravall 1997, p. 47) El Tacitismo que surgió en Italia en el siglo XVI y penetró en España, donde arraigó fuertemente (Antón Martínez, 1991) contribuyó al estudio de la política, de igual forma que lo había hecho Maquiavelo. Pero en la época de la Contrarreforma Maquiavelo era un autor prohibido y el maquiavelismo tenía entonces un sentido peyorativo, contribuyendo a la difusión de Tácito.

Hay que señalar que los autores del Barroco español utilizaron abundantemente los emblemas, incluso abusaron de ellos, pero no sólo es una característica exclusiva de los españoles. Sirva de ejemplo el emblema de la portada del Leviatán de Thomas Hobbes de mediados del siglo XVII realizado por el grabador francés Abraham Bosse (1602-1676), cuyo mote o título es "Non est potestas super terram quae comparetur ei" (No hay poder sobre la Tierra que se le

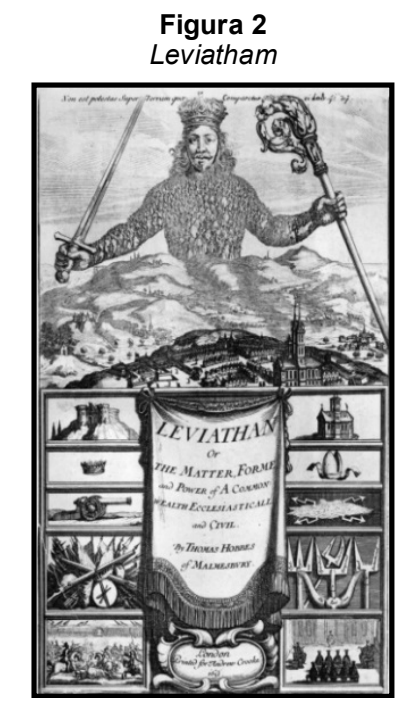

Fuente: Thomas Hobbes, Portada, 1651. compare) (Prieto, 1993: 534).

\section{LA EMBLEMÁTICA AL SERVICIO DEL SOCORRO A LOS POBRES EN EL SIGLO XVI: EL AMPARO DE POBRES DE CRISTÓBAL PÉREZ DE HERRERA}

Es conocida la polémica suscitada sobre el socorro a los pobres en la primera mitad del siglo XVI. La polémica dio lugar a toda una literatura de tipo moralista que se inicia con el trabajo de Luis Vives De subventione pauperum (1526) donde se rechaza la proposición de que todo pobre tiene derecho a pedir limosna, sugiriendo distinguir entre pobres fingidos y legítimos. Una postura que defenderá la intervención de las autoridades civiles a la hora de resolver el problema, siendo los pobres legítimos los únicos que tendrán derecho a vivir en centros de acogida y aprender un oficio. La polémica hoy en día permite obtener conclusiones esclarecedoras en lo que concierne a la actual teoría económica de los derechos de propiedad, y también respecto al debate sobre el Estado del Bienestar (Fernández Delgado, 2006b: 18).

El debate tendrá continuidad en la obra del dominico Domingo de Soto Deliberación en la causa de los pobres de 1545, un trabajo en el que cuestionará la capacidad del Estado a la hora de llevar a cabo políticas eficaces de recogimiento de pobres. El planteamiento de Domingo de Soto circunscribe el asunto de la pobreza al ámbito de los derechos de los individuos al coartar libertad individual. Será el benedictino Juan de Robles (1545) el que considerará este 
asunto de orden público, una consideración que finalizando el siglo continuará Cristóbal Pérez de Herrera (1598).

Cristóbal Pérez de Herrera fue médico, político y poeta que nació en Salamanca en 1556 donde estudió humanidades con los jesuitas y se graduó de bachiller en Artes. Graduado en Artes se matriculó en la Facultad de Medicina en la Universidad de Alcalá, estudios que continuó y terminó en la Universidad de Salamanca en 1577. En ese mismo año acudió a Madrid donde en 1580 es nombrado médico de la Casa Real, y un año más tarde protomédico de galeras, antesala del protomedicato del rey. Cuenta Gregorio Marañón en su Vida en las galeras de Felipe II, que al ser Cristóbal Pérez de Herrera protomédico de galeras de España "tenía a su cargo no sólo la inspección de los servicios sanitarios de las naves, sino que también él mismo servía en las escuadras, y, con frecuencia, no sólo como médico, sino como consejero militar y aun como jefe directo de las tripulaciones".

En 1592 abandona el oficio en galeras y se incorpora como médico de Casa y Corte en Madrid, una ciudad envuelta en un ambiente decadente provocado entre otras cosas por el desastre de la Armada Invencible (1588) y la crisis de finales de siglo. Este ambiente debió incentivarle para redactar a finales de 1592 y publicar en 1598, "por orden de Su Majestad" su famoso trabajo Discurso del Amparo de los Pobres, y reducción de los fingidos y de la fundación y principio de los Albergues de estos Reynos, y amparo de la milicia de ellos.

El trabajo de Herrera es considerado el estudio más completo sobre el problema de la mendicidad y del recogimiento de los pobres y vagabundos de finales del siglo XVI. Nos comenta Manuel Martín que, aunque la edición de 1598 es la única completa, algunos de sus capítulos ya se habían publicado con anterioridad (Martín Rodríguez, 1984: 55). Una de las principales características del trabajo, compuesto por diez discursos, es el hecho de que éstos se incorporan a la tradicional forma de exposición de la literatura emblemática. El estilo de Herrera bien puede considerarse, como hemos visto más arriba, otro ejemplo del sentido pragmático en la exposición. Se aleja de las citas de autoridades e ilustra sus discursos con historias anecdóticas de sus experiencias personales (Reeder, 2003: 685).

Con este trabajo Herrera, se incorpora a la corriente de pensamiento que junto con Vives, Robles y Giginta, lograron crear, como afirma el profesor Manuel Martín, una doctrina en la que la inmensa masa de pobres parados, que no podía ser absorbida por la precariedad de la actividades económicas, dejó de ser incompatible con la política poblacionista, que aparentemente estaba en contradicción con la existencia de éstos (Martín Rodríguez, 1984: 21).

Centrándonos en el trabajo, en el primer discurso, que tiene por emblema la justicia, se analizan no sólo los inconvenientes provocados por los mendigos fingidos a la hora de pedir limosna, sino también los trucos que éstos utilizan 
para quitársela a los verdaderos pobres. El asunto de la pobreza según Herrera abarcaba varios aspectos, desde el hecho de que existen pobres que fingen serlo, y "se dan a la mala vida, a la lujuria y al juego", hasta la "codicia insaciable, que los lleva a infligirse llagas y heridas con las que causar lástima y aumentar las limosnas". También le preocupa la nacionalidad de los indigentes ya sean turcos, protestantes franceses e ingleses que según él "traen de sus tierras ideas heréticas y perniciosas para la salvación de las almas".

En el emblema aparece la Justicia representada por una mujer vestida con toquilla en la cabeza, túnica y manto, sujetando con la mano derecha una espada con doble filo apuntando hacia arriba y una balanza en la mano izquierda. El emblema se acompaña con un soneto de D. Iván de Mendoza, marqués de Montesclaros y del Castillo de Bayuela. En este discurso Herrera despliega todo su ingenio en forma de inconvenientes contra los mendigos fingidos, describiendo con todo lujo de detalles la mala vida que llevan, la concupiscencia y las mil tretas que utilizan para parecer pobres.

Con el emblema de la Justicia quiere hacer saber que ésta debe recaer sobre los fingidos "que mendigan con malicia" y que son falsos pobres que se enriquecen a costa de las limosnas destinadas a los que verdaderamente lo son. El mote del em-

Figura 3

Amparo de pobres

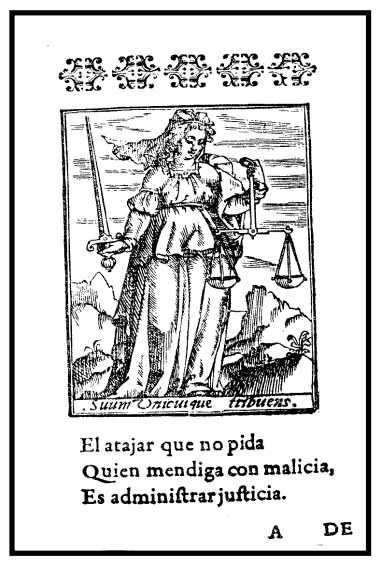

Fuente: Pérez de Herrera, C. $1598^{1}$ blema reza "Suum Unique Tribuens" (Otorgando a cada uno lo suyo).

En el segundo discurso, que incorpora un soneto de Lope de Vega, tiene un emblema que es la "Piedad de la cigüeña y el gobierno de las abejas, y el orden y la providencia de las hormigas". El emblema está formado por tres escenas, en la superior aparece una cigüeña alimentando con el pico a sus crías. En la segunda viñeta aparecen unas colmenas y volando entre ellas multitud de abejas.

\footnotetext{
${ }^{1}$ Los emblemas que a continuación se enseñan han sido extraídos de la edición de 1598 Amparo de pobres, editados por López Poza, Sagrario y Sandra $\mathrm{M}^{\mathrm{a}}$ Fernández Vales, Catálogo de ediciones digitales de libros de emblemas y obras afines accesibles en Internet /DEBOW (Digital Emblem Books on Web). 5 a edición. Julio 2013. ISBN:978-84-695-8172-8. (SIELAE http://www.bidiso.es/sielae/presentacion.htm- Universidade da Coruña - España). http://www.bidiso.es/emblematica. Hay que señalar que el título largo de la obra es Discursos del amparo de los legítimos pobres, y reducción de los fingidos: y de la fundación y principio de los Albergues destos Reynos, y amparo de la milicia dellos. por el doctor Christóval Pérez de Herrera, Protomédico por su Magestad de las galeras de España, natural de la ciudad de Salamanca. Dirigidos al poderosíssimo Príncipe de las Españas, y del Nuevo Mundo, Don Filipe III nuestro señor, \&c. Año [escudo] 1598. También se ha consultado la edición de la Biblioteca Digital Hispánica de la Biblioteca Nacional. Datos de la edición: En Madrid por Luis Sánchez, 1598.
} 
En la última imagen aparece un hormiguero del que surgen varias hileras de hormigas. El mote del emblema es "Pietate-Gubernatione-Ordine" (PiedadGobierno-Orden).

Figura 4

Amparo de pobres

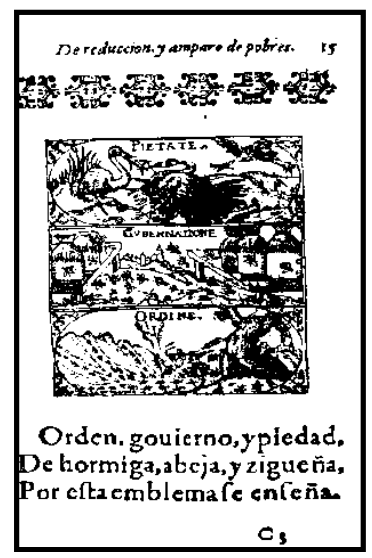

Fuente: Pérez de Herrera, C. 1598.

Con este emblema Herrera ilustra tres virtudes representadas en los tres animales: la cigüeña representa la piedad porque mantiene y cuida de sus crías. La abeja representa el gobierno porque forma parte de un Estado perfectamente estratificado y organizado a las órdenes del rey. Por último la hormiga representa el orden al desplazarse formando hileras continuas y disciplinadas.

Este discurso está dedicado al diseño de los albergues, a los pobres vergonzantes, a los cautivos y huérfanos. Con relación a los albergues sugiere que para mantener en orden a los mendigos se deben construir en cada población albergues donde se les de alojamiento y manutención. Además los mendigos deben contribuir a la mejora del local con sus propias limosnas. Cada albergue se encargaría de entregar a los verdaderos pobres algún tipo de documentación o salvo conducto que confirmase su verdadera situación y así poder mendigar. Para evitar contagios de enfermedades los albergues sólo podrían ser utilizados por los pobres sanos, los enfermos e impedidos deberían ir a los Hospitales. Para el género de pobres vergonzantes (aquellos que lo son, pero por rubor se niegan a admitirlo) el autor considera la posibilidad de crear Hermandades de Misericordia que se encargarían de mantenerlos. Pone como ejemplo la que existe en la parroquia de San Martín en Madrid. Incluye en el discurso "el socorro y remedio de los pobres encarcelados". Para éstos recomienda que se refuercen las Hermandades y que los alcaldes de la Corte y de las Cancillerías honren a los abogados de pobres. Con relación a las cárceles sugiere que los presos pobres sean visitados periódicamente por procuradores. Por último y con relación a las huérfanas, recomienda que tanto los justicias eclesiásticas como seglares vigilen que se cumplan los patronazgos y testamentos.

El "arco y las flechas de Cupido quebradas y una olla" son los objetos que integran la pintura del tercer discurso. Este discurso trata de la forma de cómo deben pedir limosna:

"otros géneros de pobres: y de cómo se han de acomodar y ocupar los reformados fingidos, y del amparo, distribución y ocupación de los niños, y niñas pobres, y huérfanos desamparados" (Pérez de Herrera, 1598: 46).

Aquí Herrera deja abierta la posibilidad de que todos aquellos peregrinos, extranjeros, estudiantes, niños, que en buena lid demuestren, ante los examina- 
dores, que se encuentran necesitados puedan pedir limosna. Con relación a los niños y niñas pobres, y huérfanos desamparados recomienda a Prelados y Corregidores que "se repartiesen" entre caballeros, ciudadanos y gentes ricas que sean. Aunque está a favor de la adopción cuando son muy pequeños, les permite pedir limosna hasta la edad de ocho años, y ocuparlos, por ejemplo en el ejército, cuando superen dicha edad. Respecto a los fingidos reformados considera que:

"ocupándolos en oficios, podrán ser honrados, y más descansados, viviendo con razón y concierto, $y$ sin tantos peligros de esa vida, y con menos enfermedades, $y$ lo más principal, con más esperanza de ver a Dios en el cielo" (Pérez de Herrera, 1598: 53).

Figura 5

Amparo de pobres

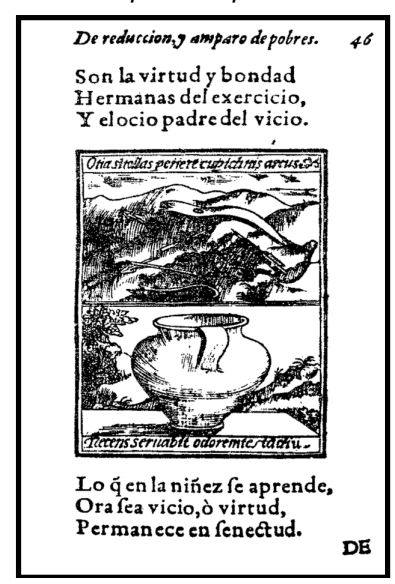

Fuente: Pérez de Herrera, C. 1598.

El emblema está dividido en dos viñetas. En la viñeta superior aparecen en el suelo un arco y dos flechas rotas; y en la viñeta inferior aparece un puchero que suponemos es de barro.

El mote de la primera viñeta es "Otia si tollas periere Cupidinis arcus" ( $\mathrm{Si}$ suprimes los momentos de ocio, pierden efectos los arcos de $\mathrm{Cu}-$ pido). El mote de la segunda viñeta es "Recens servabit odorem testa dui" (La arcilla joven conservará largo tiempo el olor del que se impregnó). Afirma López Poza (2013) que Herrera con este emblema quiere decirnos que igual que el arco y las flechas se vuelven inservibles si no se usan con frecuencia, lo mismo ocurrirá con la virtud que proviene del trabajo y la actividad, que el ocio termina por hacer al hombre vicioso. Con relación al puchero de barro, que tiene la facultad de mantener mucho tiempo el olor que se le impregnó cuando fue fabricado, nos recuerda que lo aprendido en la niñez, ya sea defecto o virtud, permanece en el hombre durante su edad adulta.

El cuarto discurso trata de la reclusión y castigo de las mujeres vagabundas y delincuentes, y tiene un emblema cuya picturae es una mano con un ojo en cada dedo:

"en cada dedo el suyo, es del castigo y reclusión de los vagabundos, para que se enmienden y vivan con regimiento" (Pérez de Herrera, 1975: 315).

El significado del emblema cuyo mote es "Vigili Labore" (Con esfuerzo atento), viene a ser que al unir trabajo y vigilancia se adquieren mejores costumbres.

Sorprende en este discurso la dureza con la que el autor trata la mendicidad femenina. El correctivo debe ser ejemplar, "que convenza a los demás de que se retraigan de la mala vida". Los castigos en ningún caso deben "atentar contra su 
honra sino encaminarlas a la reclusión como buenas cristianas en casas de labor" donde puedan regenerarse ejerciendo diversos oficios. He aquí el significado de la pintura, la mano abierta y los ojos: la vigilancia tiene que ser constante y llevada a cabo por alcaides y "mujeres de probada virtud".

Figura 6

Amparo de pobres

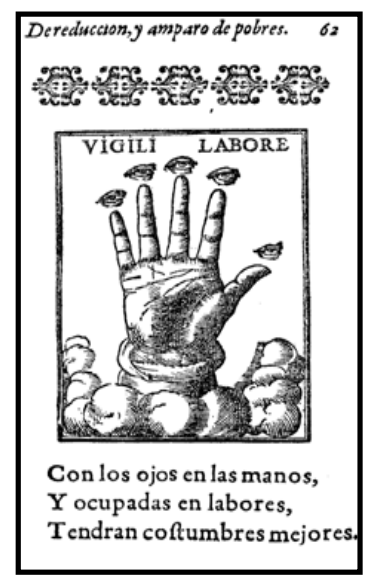

Fuente: Pérez de Herrera, C. 1598.

"Para remedio... por ley y pragmática de V.M. en cada casa capaz, y a propósito, que se llame y nombre del trabajo y labor, a donde condenen... a las vagabundas ociosas, o delincuentes de hurtos, hechicerías, o embustes, o de otros delitos, por uno, dos tres o más años, y aún por diez, conforme a sus culpas, y de por vida, a las que mereciere casi pena de muerte" (Pérez de Herrera, 1598: 65-66).

En el quinto discurso, que incorpora dos octavas escritas por su hijo, y que tiene por emblema un sol "que sale y limpia unos nublados" que nuestro autor titula: Apología pretende dar respuesta a ciertas dudas y objeciones planteadas por diversos autores a los discursos anteriores.

El significado del sol resplandeciente aplicado al objetivo del discurso expresa que la verdad de los razonamientos queda esclarecida cuando se somete a la duda y a la discusión. El mote del emblema es "Post nubila Phoebus" (Tras las nubes surge Febo, el dios Apolo personificado en sol).

Una de las objeciones a las que se enfrenta Herrera procedía de "algunos padres de la Iglesia" que defendían la idea de que el mendigo es libre de pedir limosna "como quiera". Recordemos que el dominico Domingo de Soto había publicado en 1545 su Deliberación en la causa de los pobres donde afirmaba que los pobres no podían ser obligados a no salir de sus lugares de origen. Así, "ninguna ley puede prohibir a los pobres ni hacerles raya que no salgan de sus naturalezas a pedir limosna". Ante esta objeción Herrera insiste en la idea de que controlando la mendicidad se desenmascara a los pobres fingidos. Solución que además tiene efectos beneficiosos para las arcas del municipio pues al disminuir el número de pobres el gasto destinado a los mismos disminuiría. De-

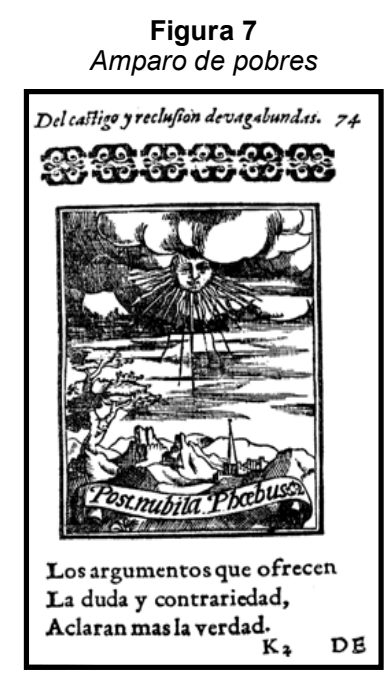

Fuente: Pérez de Herrera, C. 1598. fiende la idea de que señalar o marcar a los pobres no va en contra de los mismos sino todo lo contrario, esta medida "no es causa de males para el pobre sino 
seguridad de que no pasará hambre". Con respecto a los albergues y la posibilidad de que dentro de éstos se produzcan comportamientos censurables, el salmantino propone una serie de medidas tales como dormir con la luz encendida y aumentar la vigilancia.

El discurso sexto, con soneto de Lope de Vega, tiene por emblema "el artificio de hilar y perfeccionar la seda, es de la ejecución de todo lo que está escrito en esta materia”. En este discurso Pérez de Herrera proporciona una serie de consejos para que se agilice y se mejore la organización de las reformas necesarias para la asistencia. Consejos que abarcan desde la publicación de pragmáticas relacionadas con la asistencia, hasta dónde dirigirlas y el nombramiento de los comisarios que deben gestionar los albergues de acogida.

"Me ha parecido convendría, se sirviese V.M. de mandar y ordenar se hagan y dispongan las cosas siguientes. Que lo acordado acerca de todo ello por mandado de V.M. se publique y ejecute en las ciudades y lugares principales de estos Reinos... los

Figura 8 Amparo de pobres

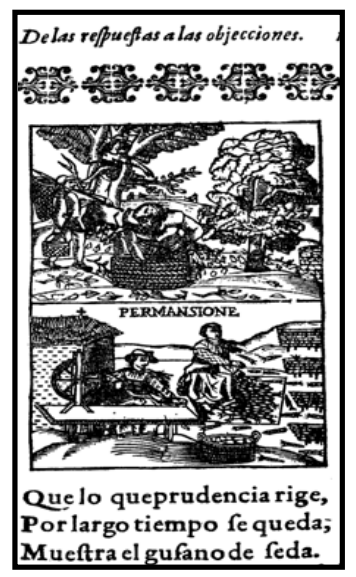

Fuente: Pérez de Herrera, C. 1598. pobres fingidos se irán de la parte donde esto se ejecutase... Que las pragmáticas que V.M. mandare pregonar ...para el día de nuestra señora de la Encarnación del año noventa y nueve..." (Pérez de Herrera, 1598: 106-107).

Figura 9

Amparo de pobres

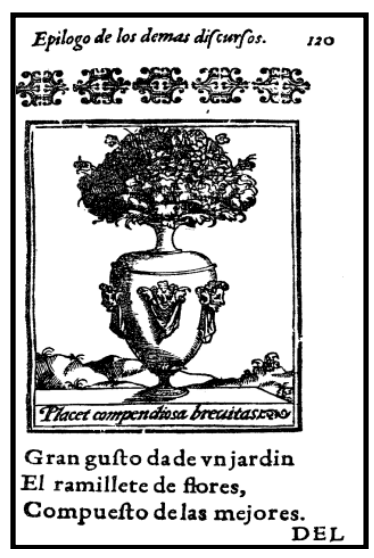

Fuente: Pérez de Herrera, C. 1598.
La pintura, cuyo mote es "Permasione" (Con persistencia), muestra la industria de la seda, desde la recolección de las hojas de la morera, la crianza del gusano y la obtención de la fibra.

De la misma forma que el gusano se oculta para elaborar los capullos a partir de los cuales se obtendrá la seda, así se debe utilizar la prudencia en todas las acciones para conseguir que sean siempre perdurables (López Poza, 2013).

El discurso séptimo, que incorpora el soneto del Doctor Antonio Daza natural de la ciudad de Ávila, es considerado por nuestro autor como la sinopsis o epílogo de los discursos anteriores. Este memorial tiene por emblema un jarrón decorado con un ramo de flores. El emblema ilustra las ventajas que se obtienen no sólo a la hora de seleccionar ideas, sino de exponerlas con claridad y brevedad. Dicha selección se asemeja a la selección de flores que se realiza en 
el ramo. El epigrama nos esclarece el significado: "Gran gusto da de un jardín el ramillete de flores compuesto de las mejores".

En este discurso se facilita diversas propuestas y advertencias sobre los seis discursos anteriores. Con relación a las proposiciones invita a los pobres mendigantes a que sean buenos cristianos, que se los acoja en albergues, y que en ellos un sacerdote o gerente les gobierne.

Persiste en la idea de que aquellos que no pueden trabajar puedan pedir limosna con una señal identificativa, pero que no anden vagabundos. Trata de que se enseñe un oficio a los hijos de los mendigos, y que se creen cofradías o gremios con el fin de proporcionarles empleo, insistiendo en el control de la mendicidad y que la justicia recaiga sobre el pobre fingido.

Con relación a las advertencias aconseja que se restablezca la caridad, mejorar la "quietud" de las iglesias y que los pobres se confiesen más a menudo. Vuelve a insistir en el hecho de que no se deben utilizar los albergues como hospitales, y que los pobres casados y conocidos puedan vivir en su propia casa llevando un distintivo que los identifique. Aconseja que los bienes de los pobres cuando fallezcan sean de utilidad pública, y que los albergues tengan una sala de incurables para que éstos vayan a los hospitales. Persuade para que los pobres no mueran sin recibir sacramento, y que se hagan sus reformas con el mayor rigor posible desde el principio, y, por supuesto, se reduzca el número de mendigos fingidos.

El emblema del discurso octavo está compuesto por un galeón que navega con todo el velamen

Figura 10 Amparo de pobres

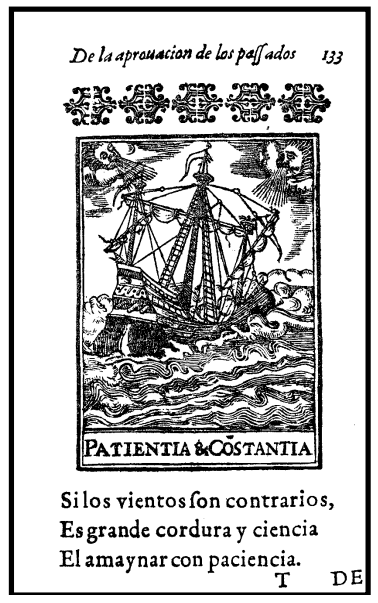

Fuente: Pérez de Herrera, C. 1598. recogido en medio de una gran tormenta en un mar bravío y fuertes vientos. Vientos representados mediante el soplo de dos cabezas que surgen entre nubes, y cuyo mote es "Patientia et constantia" (Paciencia y constancia).

En este discurso Herrera trata:

"De algunas relaciones, aprobaciones, instrucciones y cartas, en confirmación, y aprobación de los discursos para el negocio del amparo de los legítimos pobres y reformación de los fingidos de estos Reinos" (Pérez de Herrera, 1598: 134).

El discurso incorpora un conjunto de advertencias de diversos miembros del Consejo de Castilla respecto al socorro a los pobres, además, y tomando como ejemplo el albergue de la ciudad de Madrid, recomienda de nuevo la construcción de escuelas para enseñar oficios. Con relación a los miembros del Consejo de Castilla, el discurso agrega el memorial por el que se solicitaba al rey Felipe 
II llevar a cabo la propuesta de Herrera, incluyendo además diversas aprobaciones dadas por varios catedráticos y teólogos.

El discurso, al contemplar las disposiciones del Consejo de Castilla, muy severas respecto a la pobreza, viene a confirmar que el asunto del socorro a los pobres a finales del XVI adquiere rango de problema económico y social. Poco a poco éste tema va despojándose de su aureola evangélica y aparece como una peligrosa lacra (Cavillac, 1975: lxxxvii).

En este sentido, desde 1523 van a ir apareciendo numerosas peticiones en Cortes (Valladolid, 1523; Toledo 1525; Madrid; 1528 y 1534) que exigían acometer desde otra perspectiva el asunto de la pobreza. De ahí la pragmática de 1525 por la que se obligaba a los pobres a no mendigar fuera de su lugar de residencia.

Los reiterativos incumplimientos de la pragmática de 1525 dieron lugar a que el Consejo Real, el 24 de agosto de 1540, dispusiera un nuevo Título "Del socorro y recogimiento de los pobres" donde establecía el límite máximo para poder mendigar, límite que quedaba establecido en un radio de treinta kilómetros desde la residencia de origen. Reiteraba que ninguna persona podía pedir limosna sin acreditación. Además incorporaba el conjunto de requisitos necesarios para conseguir dicho salvo conducto, requisitos que incluían el estar confesado y comulgado o encontrarse en situación de pestilencia y necesidad. En el Título queda tajantemente prohibida mendigar acompañado de niños, y obligaba a que éstos aprendieran un oficio. Los Prelados y los Justicias, en sus respectivas diócesis y jurisdicciones, debían, no sólo administrar los hospitales, sino también intervenir en las rentas destinadas al socorro de pobres. (Nueva Recopilación, [1567] (1982), Vol. i, tit. xii: 52-58), y (Novísima Recopilación, [1801](1992), t. iii, lib. vii, tit. xxxix: 703-707).

El discurso noveno tiene un emblema ilustrado con un San Miguel Arcángel expulsando a Lucifer del cielo. Trata el asunto de la ayuda a los militares que, o bien por invalidez o por vejez no podían

Figura 11 Amparo de pobres

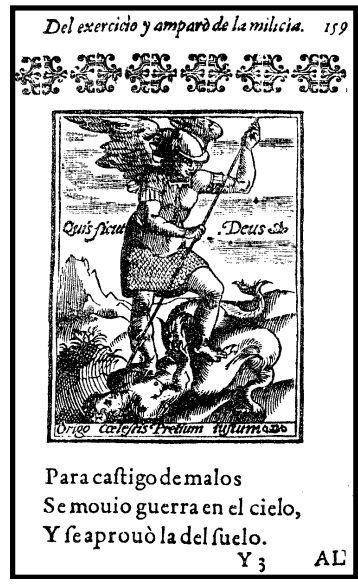

Fuente: Pérez de Herrera, C. 1598. seguir en el ejército. Intentaba llamar la atención del rey para que mitigara los problemas de la milicia, un problema que eleva al mismo rango que el del socorro a los pobres. Este discurso viene a complementar al discurso tercero, donde nuestro autor señalaba la necesidad de que el ejército se nutriera de pobres fingidos, y de niños mayores de ocho años. 
Considera además que la fabricación de armamento o el estudio de ingenierías en escuelas técnicas constituían salidas profesionales adecuadas para los pobres fingidos y los niños pobres. Asimismo, en este trabajo señala la necesidad de apoyar y ayudar a la milicia creando una especie de Hermandad o Congregación, con objeto de amparar al ejército, y promover el valor entre los soldados. Detalla una serie de incentivos encaminados a este fin tales como premios, ayudas a la vejez, o mayor consideración social por los militares. El emblema justifica estos propósitos. Como nos cuenta la profesora López Poza (2013), la imagen de San Miguel hiriendo al demonio demuestra que Dios aprueba toda guerra ya sea en la tierra o en el cielo, siempre y cuando vaya destinada a destruir a malvados y herejes.

El último arbitrio tiene por emblema un radiante sol con rostro humano que con sus rayos enciende una antorcha y que nuestro autor describe como:

"llama hacha que toma lumbre y se enciende de un sol que significa el ingenio humano" (Pérez de Herrera, 1975: 316).

Figura 12 Amparo de pobres

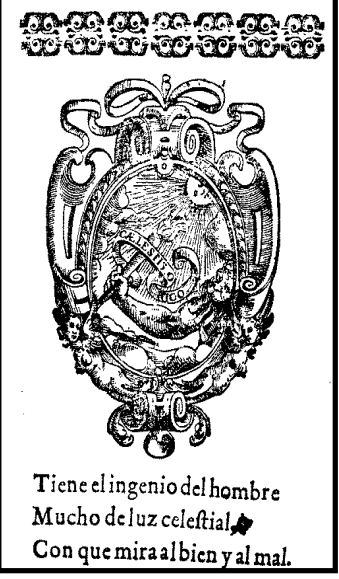

Fuente: Pérez de Herrera, C. 1598.
Detallando el dibujo, la antorcha está sujeta por un brazo cubierto con una indumentaria militar. En la imagen aparece la inscripción "Caelestis origo" (Origen celeste). El objetivo de este discurso es reafirmar todo lo que se había dicho en los nueve discursos anteriores.

Con el Amparo de pobres Herrera culmina el proceso de secularización de la beneficencia iniciado en 1526 por Luis Vives. Esta evolución secular, aunque no fue continua, permitió adentrarse en los inconvenientes que suscitaba la reforma social.

Inconvenientes que desde los tiempos de Vives habían venido señalándose y que caracterizaron el debate. Como hemos tenido ocasión de ver, el trabajo de Domingo de Soto puede considerarse paradigmático en este sentido. Soto publicó su Deliberación tras la promulgación en Medina del Campo de las disposiciones aprobadas por el Consejo Real en 1540. Como señala el profesor Victoriano Martín (1999, 295-339), Domingo de Soto se sabía teólogo de la Iglesia Católica y reconociendo las dos fuentes de revelación, la Escritura y la tradición, afirmará que los pobres no pueden ser obligados a no salir de sus lugares de origen. Seguramente estaba siguiendo las enseñanzas de su maestro Francisco de Vitoria sobre el derecho de gentes, siéndolo además de derecho natural que cada cual circule libremente por donde quisiere. 
Como hemos visto en el emblema quinto, las objeciones a estas disposiciones eran habituales, Herrera las conocía, las discutía y aún así las incorporó en el emblema octavo, lo que nos lleva a pensar que el Amparo de pobres es una reafirmación, a finales del siglo XVI, de las disposiciones del Consejo, alejando el asunto del ámbito de los derechos de los individuos y acercándolo al ámbito del orden público.

\section{EMBLEMAS E IDEAS ECONÓMICAS EN LAS EMPRESAS POLÍTICAS DE SAAVEDRA FAJARDO: MONEDA, COMERCIO, HACIENDA Y POBLACIÓN}

Fue Diego Saavedra Fajardo (1584-1648) un importante, influyente y acreditado diplomático español "Del Consejo de su Magestad en el Supremo de las Indias y su Embajador Plenipotenciario en los Treze Cantones, en la Dieta Imperial de Ratisbona". Contextualizando su vida y obra llama la atención el hecho de que coincidió en vida con tres reyes, Felipe II (1527-1598), Felipe III (1578-1621) y Felipe IV (1605-1665). Siendo ya adolescente le tocó vivir las postrimerías del reinado de Felipe II (1556-1598) y la entronización de su sucesor Felipe III. Del reinado de Felipe III (1598-1621) destaca desde el punto de vista económico la expulsión de los moriscos, la controvertida decadencia económica y la famosa Consulta de febrero de 1619 por la que el Consejo de Castilla presentó una serie de remedios con los que poder afrontar "los diversos males que afectaban al reino". Con relación al reinado de Felipe IV (1621-1665) cabe destacar la rebelión de Cataluña y Portugal, el fin de la tregua de los doce años con Holanda, la firma de las alianzas entre Francia, Inglaterra y Holanda, la perdida de Portugal, la insurrección de Nápoles y la Paz de Westfalia (1643).

Nace Diego Saavedra Fajardo en la localidad murciana de Algezares en 1584, fue el segundo hijo de una familia hidalga y adinerada. Estudió Derecho Civil y Canónigo en la Universidad de Salamanca (1601-1608), donde recibió órdenes menores. En 1610 entra en la carrera diplomática como notario del cardenal Gaspar de Borja. Entre 1610 a 1630 vivió en Italia donde fue nombrado secretario de embajada en Roma, y desempeñó funciones diplomáticas en Nápoles y Sicilia. Fue ministro entre 1663 y 1640 en Baviera, Ratisbona, Milán, Borgoña y Viena. Fue plenipotenciario español en el Congreso de Muster en las negociaciones que ponían fin a la guerra de los Treinta Años con la Paz de Westfalia. De vuelta a Madrid, es nombrado supernumerario del Consejo de Indias e introductor de embajadores (1646-1648). En 1640 recibió el título de Caballero de la Orden de Santiago.

Saavedra Fajardo fue un polifacético autor que escribió desde poesía hasta libros satíricos y de ciencia política. Sus poemas aparecen en los preliminares del libro Desengaño de Fortuna (1611) de Gutierre Marqués de Careaga y en las Tablas poéticas (1614) de Francisco Cascales. Otro poema aparece en El 
anfiteatro de Felipe el Grande (1631). También es autor de Locuras de Europa (1643-45), Corona gótica, castellana y austriaca (1646), República literaria (1665), Introducciones a la Política y Razón de Estado del Rey Católico Don Fernando (1631). Nos cuenta López Poza (1999) que muy probablemente Saavedra no viera publicada en vida ninguna obra suya a excepción de dos poemas circunstanciales y algunos opúsculos satíricos y panfletos anónimos. Con relación a Introducciones a la Política y Razón de Estado no llegó a la imprenta hasta 1853, y parece que fue el germen de lo se desarrollaría luego como la Idea de un príncipe político christiano, puesto que hay pasajes íntegros de la Razón de Estado que pasaron a formar parte de las empresas 3, 4, 7, 12, 18, 25 y 60. Muy poco después de la Razón de Estado comenzó la redacción de Idea de un príncipe político christiano representada en cien empresas (también denominada Empresas políticas) de la que existen dos ediciones. La editio princeps se publicó en Mónaco, la capital bávara que hoy es Múnich en la imprenta de Nicolao Enrico, en 1640. La segunda edición es de 1642 en cuya portada aparece "En Mónaco A 1 de Marzo de 1640. En Milán a 20 de Abril de 1642". Como nos enseña López Poza, la primera edición revela más espontaneidad, menos preocupaciones, y los cambios introducidos en la segunda indica que actúa advertido, aleccionado de que puede tener problemas si sigue sus primeras intenciones, si no dosifica convenientemente las fuentes profanas con las sagradas, si no elimina motivos mitológicos de la picturae, si no matiza ciertas afirmaciones sobre personajes políticos y lima sus posturas tacitistas que pueden confundirse con "maquiavelistas" (López Poza, 1999: 20, 135-136).

A pesar del contenido eminentemente político de las Empresas políticas Saavedra incorporó en este trabajo reflexiones propias de un atento analista económico, unas reflexiones que seguramente añadió porque existían suficiente argumentos de peso que demandaban un lugar en su obra. Debieron ser un acicate la Consulta de 1619, los excesos en la emisión de moneda de vellón durante los reinados de Felipe III y Felipe IV, la despoblación, la pobreza, el aparente abandono de los sectores productivos y la continua imposición de tributos sin contar con el consentimiento de los súbditos.

Así, la Empresa 69 cuyo emblema tiene por motivo una mano que sale de una nube y sujeta una espada y una rama de frutos de oro situada sobre un globo terráqueo, cuyo mote es "Ferro et auro" (Hierro y oro), está dedicada a los efectos de los metales preciosos sobre la economía, la inflación, la saca y el envilecimiento de la moneda.

Mencionaba la admiración que se sentía en Castilla por los metales preciosos venidos de América "la mercancía con espíritus nobles trocó los bancos por sillas jinetas, y salió a ruar por las calles", pero no sólo esto sino que la exportación o saca de moneda estaba servida porque "las monedas de oro despreciaron el villano parentesco de la liga, y no admitiendo el de otros metales, quedaron 
puras y nobles, y fueron apetecidas y buscadas por varios medios de las naciones". Además, y siguiendo la tradición cuantitativista de la Escuela de Salamanca supo ver la conexión entre el nivel de precios y la cantidad de oro y plata en circulación puesto que "las cosas se ensoberbecieron, y desestimada la plata y el oro, levantaron sus precios", así al aumentar la cantidad de metales preciosos, su valor disminuyó y los precios de las mercancías nominados en esa unidad de cuenta aumentaron.

Su fino análisis no terminó aquí, también en esta Empresa denunció el envilecimiento de la moneda consecuencia de políticas de aumento del gasto público. El aumento del gasto público dio lugar al "empeño y éste a los cambios y usuras. Creció la necesidad, y obligó a costosos arbitrios. El más dañoso fue la alteración de las monedas, sin advertir que se deben conservar puras". Denunció estas prácticas llevadas a cabo por Felipe III, con razón porque este rey ordenó el 13 de junio de 1602 que la moneda de vellón fabricada a partir de ese momento fuera únicamente de cobre, sin cantidad alguna de plata, y, además, con un

Figura 13 Empresa 69, Empresas politicas

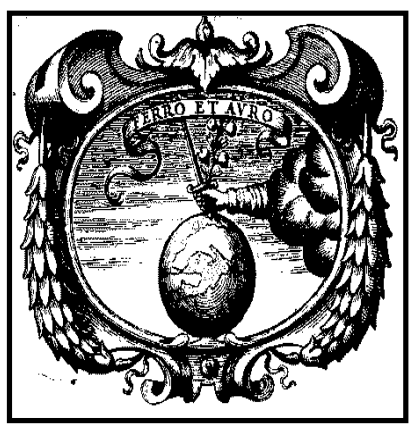

Fuente: Saavedra Fajardo, D. $1640{ }^{2}$ peso reducido a la mitad con respecto a las anteriores emisiones Además, la Corona, el 18 de septiembre de 1603, decidió doblar el valor de toda la moneda de vellón acuñada antes de 1602 para evitar «la comfusión e yncombinienttes que de forma diferente la una de la ottra podrían resultar». Se ordenaba a los particulares la entrega en un plazo de treinta días de toda la moneda de vellón vieja en las casas de moneda donde sería resellada de acuerdo al peso y valor establecido en la pragmática de junio del año anterior. Las piezas de 4 maravedíes pasaron a 8, las de 2 a 4 y las de 1 a 2. (Santiago Fernández, 2000: 58-60).

A todo lo anterior hay que añadir, y que bien supo ver Saavedra Fajardo, que los extranjeros al reconocer la sobrevaloración de la moneda de vellón trajeron cobre y sacaron "la plata y el oro y las demás mercancías, y hicieron más daño que si hubieran derramado en ella todas las serpientes y animales ponzoñosos de África". Como señala la profesora Marjorie Grice-Hutchinson, refiriéndose a la Empresa 69, no parece que el análisis de la inflación de de Saavedra Fajardo estuviera muy equivocado. La decadencia económica de España fue explicada

\footnotetext{
${ }^{2}$ Los emblemas que a continuación se muestran han sido extraídos de la edición de 1642 de Empresas políticas editada por López Poza, Sagrario y Sandra $\mathrm{M}^{\mathrm{a}}$ Fernández Vales, Catálogo de ediciones digitales de libros de emblemas y obras afines accesibles en Internet /DEBOW (Digital Emblem Books on Web). 5a edición. Julio 2013. ISBN:978-84-695-8172-8. (SIELAE http://www.bidiso.es/sielae/presentacion.htm, Universidade da Coruña - España). http://www.bidiso.es/emblematica. Sobre la influencia de los emblemas de Jacob Bruck en Saavedra Fajardo ver González de Zárate (1982).
} 
en términos similares por muchos de los economistas políticos de la última parte del siglo XVII y XVIII (Grice-Hutchinson, 1982: 233). Además no debemos olvidar que las necesidades financieras al comienzo del reinado de Felipe IV eran muchas y las emisiones de vellón no se interrumpieron, es más, lo que hasta entonces había sido un recurso empleado tan solo en momentos de apuros quedó convertido en algo permanente y fue utilizado de forma ininterrumpida (Santiago Fernández, 2000:86).

Figura 14

Empresa 68, Empresas politicas

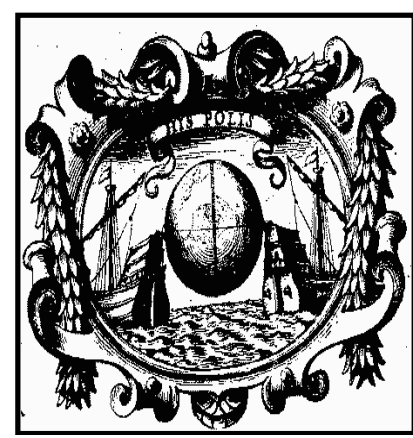

Fuente: Saavedra Fajardo, D. 1640.
La Empresa 68 está dedicada al comercio. El motivo de este emblema es un gran esfera terrestre sujetado por sus polos por las popas de dos barcos que se encuentran sobre el mar. El mote del emblema es "His polis" (Con estos polos), y la escena simboliza la importancia de la navegación para el comercio y el dominio militar. Comenta López Poza que el cuerpo de la empresa muestra la paradoja de que, a pesar de la movilidad de las naves (y precisamente por ella), sostienen y dan firmeza a los imperios (Saavedra Fajardo, 1999a: 774)

La enseñanza de Saavedra es clara, evitar que España perdiera su hegemonía sobre el Mediterráneo y el océano Atlántico, "Si le falta a España los dos polos del mar Mediterráneo y Océano, luego caería su grandeza". No le tiembla la mano a la hora de sugerir que se impida a otras naciones la navegación por las rutas que transitan los navíos españoles: "La disposición es grande, y mucha la comodidad de los puertos, para mantenellas y para impedir la navegación a las demás naciones que se enriquecen con ella". Como buen mercantilista en este asunto el objetivo es claro, hacer de España una potencia exportadora, no sólo a Indias, sino a toda Europa. Se queja de la importación de valor añadido y de la exportación de materias primas por las consecuencias negativas que dicho comercio tiene sobre la industria española:

"Con inmenso trabajo y peligro traemos a España de las partes más remotas del mundo los diamantes, las perlas, los aromas y otras muchas riquezas. Y, no pasando adelante con ellas, hacen otros granjería de nuestro trabajo, comunicándolas a las provincias de Europa, África y Asia. Entregamos a genoveses la plata y el oro con que negocien, y pagamos cambios y recambios de sus negociaciones. Salen de España la seda, la lana, la barrilla, el acero, el hierro y otras diversas materias. Y volviendo a ella labradas en diferentes formas, compramos las mismas cosas muy caras por la conduta y hechuras, de suerte que no es costoso el ingenio de las demás naciones. Entran en España mercancías que, o solamente sirven a la vista o se consumen luego, y sacan por ellas el oro y la plata" (Saavedra Fajardo, 1999a: 778-779). 
Se trata del sempiterno lamento arbitrista que consideraba perjudicial el comercio con los extranjeros aventurando un política comercial más adecuada que tratara de prohibir tanto la importación de productos manufacturados foráneos, como la exportación de materias primas, con la intención de generar empleo en el interior, disminuir la ociosidad y fomentar los sectores productivos.

Estos argumentos entroncan, como nos enseña el profesor Luis Perdices, con los razonamientos de los industrialistas del denominado grupo de Toledo, que son los que más se van a ocupar de la política comercial exterior como un obstáculo al crecimiento económico (Perdices, 1996: 116).

La Empresa 67 está dedicada al sistema fiscal. Así, la moderación impositiva y el principio del consentimiento van a vertebrar esta cuidadosa advertencia. El emblema que lo acompaña tiene como motivo un árbol podado del que cuelga en una de sus ramas una enorme podadera, y cuyo mote es "Poda no corta".

Figura 15

Empresa 67, Empresas políticas

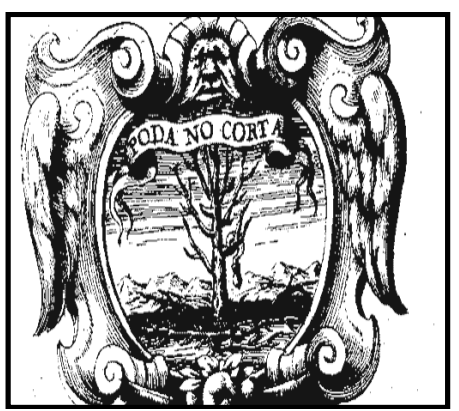

Fuente: Saavedra Fajardo, D. 1640.

El autor pretende enseñarnos que en la poda y no en el corte reside la diferencia entre el "señor natural y el tirano" a la hora de imponer y exigir impuestos. Igual que el labrador se ha de comportar el rey, que no corta por el tronco el árbol sino por las ramas, "y no todas, antes las deja de suerte que puedan volver a brotar".

A lo largo del discurso la moderación en la exigencia de los impuestos es la norma puesto que así "deuda es natural de los vasallos concedellos, y especie de rebelión el negallos". Además el fin de estos está claro "no puede haber paz sin armas, ni armas sin sueldos, ni sueldos sin tributos", un fin que ha de adecuarse a la moderación en el gasto público, que como hemos visto anunció en la empresa sesenta y nueve. Cabe recordar en el Consejo de Castilla en la Consulta de 1619 disponía que la relativa despoblación se debía fundamentalmente a la excesiva cantidad de impuestos que recaían en el pueblo, lo que propiciaba la emigración hacia aquellas zonas en las que la presión fiscal era menor.

Además afirmaba que "no es buena razón de Estado tener con tributos muy pobres a los vasallos". Aquí Saavedra utiliza el concepto de razón de Estado, concepto que emplea con mucha frecuencia a lo largo de la obra. Hay que señalar que hacia 1640 el concepto de la razón de Estado, concepto que nace de la influyente obra de Giovanni Botero La razón de Estado (1589), era utilizado con profusión por los autores políticos de la época y Saavedra Fajardo no va a ser una excepción. 
La distinción entre una buena razón de Estado y una mala razón de Estado fue habitual entre los tratadistas políticos del siglo XVII. La mala o falsa razón de Estado es la defendida por Maquiavelo que se concibe como una mera técnica de adquisición, conservación y aumento del poder sin que la ética juegue ningún papel. Por el contrario, la buena y verdadera razón de Estado, que sigue siendo una técnica de conservación y aumento del poder, tiene unos límites precisos que vienen marcados por la moral (Segura, 1994: 371). Así, la característica del Barroco fue el surgimiento de toda una literatura que rechazaba las doctrinas políticas de Maquiavelo basadas en la "razón de Estado", para apoyarse en un pensamiento -la buena razón de Estado de Botero-, donde la política quedaba siempre subordinada a la moral (Abellán, 1996: 240). Sostiene el profesor Maurizio Viroli en su estudio del proceso de transición de la política a la razón de Estado, que por estas razones Giovanni Botero fue considerado responsable de una ideología que fracturó la comprensión tradicional de la política y acusado de defender prácticas nefastas. (Viroli, 1992: 272-274). El profesor Quintín Skinner afirma que en términos generales, la razón de Estado vino a significar una pérdida de prestigio con importantes repercusiones en el ámbito de la libertad política (Skinner, 1992: 1). Además, la razón de Estado vino a suponer, en el ámbito del pensamiento económico, una ruptura en el siglo XVII con la tradición escolástica precedente (Fernández Delgado, 2006a).

Con relación al principio del consentimiento, Saavedra Fajardo se une a la lista de autores cuyo más ilustre antecesor en el siglo XVII se encuentra en Juan de Mariana y que van a defender el principio fundamental por el cual el rey no puede imponer tributos sin el consentimiento de los ciudadanos:

"Cuando el reino se hubiese dado con condición que sin su consentimiento no se pueden echar tributos, o se le concediese después con decreto general, como se hico en las Cortes de Madrid en tiempos del rey don Alfonso Undécimo, o adquiriese por prescripción inmemorial este derecho, como en España y Francia, en tales casos sería obligación forzosa esperar el consentimiento de las Cortes" (Saavedra Fajardo, 1999a: 769).

Este principio, que aparece formulado desde comienzos del siglo XIV (Sureda Carrión, 1949: 153) y que el profesor Sabine sitúa en el ámbito de la controversia que siguió a los escritos de Guillermo de Occam sobre la autoridad papal absoluta el denominado conciliarismo, significó para la historia de las ideas políticas el primer gran debate entre constitucionalismo y absolutismo y que preparó y difundió ideas que fueron utilizadas en las luchas posteriores (Sabine, 1980: 235-245).

En la influyente Empresa 66 Saavedra Fajardo muestra su preocupación por la despoblación de España,

"La fuerza de los reinos consiste en el número de los vasallos. Quien tiuene más, es mayor príncipe, no el que tiene más Estados, porque éstos no se defienden ni ofenden por sí mismos, sino por sus habitadores, en los cuales tienen un firmí- 
simo ornamento. Y asi lo dijo el emperador Adriano que quería más tener abundante de gente en el imperio que de riquezas. En la multitud dellos consiste la dignidad del príncipe, y en la despoblación su ignominia”. (Saavedra, Fajardo, 1999a: 758).

El emblema tiene por motivo un plantel de árboles nuevos frente a un grupo de árboles muertos, representando la necesaria sucesión de la población que

Figura 16

Empresa 66, Empresas politicas

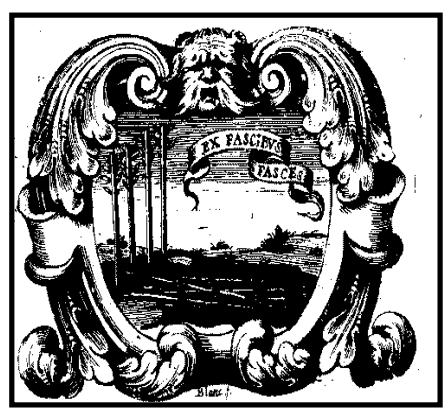

Fuente: Saavedra Fajardo, D. 1640. envejece, una sucesión ordenada y no dejada al azar. El lema del emblema es "Ex fascibus fasces" (De las varas surgen varas).

En esta empresa sigue la misma clasificación que realiza Giovanni Botero respecto a las causas que pudieran explicar la ruina de los Estados, esto es, distingue entre factores intrínsecos y extrínsecos (Fernández Delgado, 2006a: 244). Según Saavedra Fajardo la despoblación es debida a dos géneros de causas: externas e internas. Las externas son la guerra y las colonias. "La guerra es un monstruo que se alimenta con la sangre humana...Las colonias no se pueden mantener sin gran extracción de gente". Con relación a las causas internas, son "los tributos, la falta de cultura de los campos, de las artes, del comercio, y del número excesivo de los días feriados"; y añade además el exceso de gente en la Corte, los "fidecomisos o mayorazgos" y la escasez de matrimonios.

Para nuestro autor el poder del Estado radica en la cantidad de población que éste pudiera tener. Aunque se limitó a hacer una serie de comentarios sensatos que no acompañó de razonamientos analíticos, encontró la fórmula para resolver la contradicción entre los valores religiosos tradicionales del celibato y los postulados políticos de los nuevos estados nacionales que propugnaban una población abundante (Martín Rodríguez, 1984: 90-91).

\section{CONCLUSIÓN}

Cristóbal Pérez de Herrera y Diego Saavedra Fajardo escribieron en una época donde se van a producir grandes cambios en España en general y en Castilla en particular. Castilla había sido en el siglo XVI el centro de un poderoso Imperio y en poco tiempo se va a producir su deterioro económico y político, un deterioro que dio lugar a una gran cantidad de reflexiones con la intención de encontrar los remedios adecuados para salir de él. Nuestros autores, en sus respectivos trabajos, quisieron llamar la atención de las autoridades para que con mano firme dirigieran la recuperación que a la postre colocó en serias dificultades a la economía española. No sabemos si lo consiguieron pero lo que sí sabe- 
mos en que no cejaron en su empeño. Inmersos en la literatura de espejo de príncipes asuntos tales como la pobreza, la asistencia social, la inflación, los impuestos, el comercio, nutrieron sus respectivos trabajos. Trabajos que utilizaron el nuevo método de expresión fomentado por Alciato (Ledda, 1996: 45). Así, la justicia representada en bellas mujeres, cigüeñas, abejas, hormigas, galeones a la deriva, ángeles expulsando a demonios, hermosas flores, soles faciados, flechas de Cupido, esferas terrestres y cargueros mercantes, van a acompañar sus trabajos con la intención de llamar la atención de los lectores avisados.

\section{REFERENCIAS BIBLIOGRÁFICAS}

ABELLÁN, J. L. (1996): "El Barroco tiene manifestaciones políticas", en Historia del Pensamiento Español, de Séneca a nuestros días, Madrid, Espasa Calpe, pp. 231244.

ALCIATO, A. (1549): Los emblemas de Alciato, en López Poza, Sagrario y Sandra $M^{a}$ Fernández Vales, Catálogo de ediciones digitales de libros de emblemas y obras afines accesibles en Internet /DEBOW (Digital Emblem Books on Web). $5^{\text {a }}$ edición. Julio 2013. ISBN: 978-84-695-8172-8. (SIELAE, http://www.bidiso.es/sielae/ presentacion.htm, Universidade da Coruña - España). http://www.bidiso.es/ emblematica [29/08/13]

ANTÓN MARTÍNEZ, B. (1991): El Tacitismo en el siglo XVII en España. El proceso de receptio. Valladolid. Universidad de Valladolid. Caja de Salamanca y Soria.

CAVILLAC, M. (1975): "Ensayo preliminar", en Pérez de Herrera, C. (1975) [1598]: Amparo de Pobres, edición de M. Cavillac. Madrid, Espasa Calpe.

CHARTIER, R Y ESPEJO, C. (2012): La aparición del periodismo en Europa. Comunicación y propaganda en el Barroco, Madrid, Macial Pons Historia.

DARDO PÉREZ GUILHOU, (2009): "Saavedra Fajardo y la Razón de Estado" en Empresas políticas, №. 12, págs. 111-118.

FERNÁNDEZ DELGADO, R. (2006a): Liberalismo y estatismo en el siglo de oro español. Un estudio comparado del pensamiento económico de Juan de Mariana y de Sancho de Moncada, Madrid, Unión Editorial.

FERNÁNDEZ DELGADO, R. (2006b)“La Escuela de Salamanca”, en Escuelas de pensamiento económico, Madrid, Ecobook.

GONZÁLEZ DE ZÁRATE, J.M. (1982): "Los emblemas de Jacob Bruck inspiran a Saavedra Fajardo", en Boletín del seminario de estudios de arte y arqueología, 48, págs. 291-299.

GRICE-HUTCHINSON, M. (1982): El Pensamiento económico en España (1177-1740), Barcelona, Crítica.

HAFTER, M.Z. (1966): Gracián and perfection. Spanish moralist of the seventeenth century, Cambridge, Mass., Harvard University Press, pp. 49 y ss.

LALINDE ABADÍA, J. (1983): Derecho histórico español, Barcelona, Ariel 
LEDDA, G. (1996): Emblemas y configuraciones emblemáticas en la literatura religiosa y moral del siglo XVII, Actas del IV Congreso Internacional de la Asociación Internacional Siglo de Oro (AISO), Alcalá de Henares, María Cruz García de Enterría (ed. lit.), Alicia Cordón Mesa (ed. lit.), Vol. 1, 1998, págs. 45-74.

LÓPEZ POZA, S Y FERNÁNDEZ VALES S. Ma . Catálogo de ediciones digitales de libros de emblemas y obras afines accesibles en Internet / DEBOW (Digital Emblem Books on Web). $5^{\text {a }}$ edición. Julio 2013. ISBN: 978-84-695-8172-8. (SIELAE http://www.bidiso.es/sielae/presentacion.htm, Universidade da CoruñaEspaña). http://www.bidiso.es/emblematica

LÓPEZ POZA, S. (2012) "Empresas, emblemas, jeroglíficos: Agudezas simbólicas y comunicación conceptual", en La aparición del periodismo en Europa. Comunicación y propaganda en el Barroco, Madrid, Marcial Pons Historia, pp. 37-84.

LÓPEZ POZA, S. (1999): "Introducción", en Diego Saavedra Fajardo, Empresas políticas. Edición, anotación y estudio de Sagrario López Poza, Madrid, Cátedra.

MARAVALL, J.A. (1997): Teoría del Estado en España en el siglo XVII, Madrid, Centro de Estudios Constitucionales, (pp. 47-71).

MARTIN MARTÍN, V. (1999): "La controversia sobre los pobres en el siglo XVI y la doctrina sobre la propiedad", en E. Fuentes Quintana (ed.), Economía y economistas españoles, t. II, Barcelona, Galaxia Gutemberg-Círculo de Lectores, pp. 295-339.

MARTíN RODRÍGUEZ, M. (1984): Pensamiento económico español sobre la población. De Soto a Matanegui, Madrid, Pirámide.

NOVÍSIMA RECOPILACIÓN [1801] (1992), Madrid, Área de Programación Editorial del Boletín Oficial del Estado y NUEVA RECOPILACIÓN [1567] (1982), Valladolid, Editorial Lex Nova.

PERDICES DE BLAS L. (1996): La economía política de la decadencia de Castilla en el siglo XVII. Investigaciones de los arbitristas sobre la naturaleza y causas de la riqueza de las naciones, Madrid, Editorial Síntesis.

PERDICES DE BLAS L. Y REEDER, J. (2003): Diccionario de Pensamiento Económico en España, 1500-2000, Madrid, Editorial Síntesis-Fundación ICO.

PÉREZ DE HERRERA, C. (1598): Discursos del amparo de los legitimos pobres y reduccion de los fingidos y de la fundacion y principio de los albergues destos reynos y amparo de la milicia dellos. Madrid, Luis Sánchez. Biblioteca Digital Hispánica de la Biblioteca Nacional.

PÉREZ DE HERRERA, C. (1975) [1598]: Amparo de Pobres, edición de M. Cavillac. Madrid, Espasa Calpe

PÉREZ DE HERRERA, C. (1975) [1598]: Amparo de Pobres, en López Poza, Sagrario y Sandra $\mathrm{M}^{\mathrm{a}}$ Fernández Vales, Catálogo de ediciones digitales de libros de emblemas y obras afines accesibles en Internet /DEBOW (Digital Emblem Books on Web). $5^{\mathrm{a}}$ edición. Julio 2013. ISBN:978-84-695-8172-8. (SIELAE http://www.bidiso.es/sielae/ presentacion.htm, Universidade da Coruña - España). http://www.bidiso.es/emblematica [29/08/13]

PRIETO, F. (1993): Historia de las ideas y de las formas políticas, III, Edad Moderna (1. Renacimiento y Barroco), Madrid, Unión Editorial, (p.345).

REEDER, J. (2003a): "Debate sobre el socorro a los pobres", en Diccionario de Pensamiento Económico en España, 1500-2000, Madrid, Editorial Síntesis-Fundación ICO.

REEDER, J. (2003b): "Saavedra Fajardo", en Diccionario de Pensamiento Económico en España, 1500-2000, Madrid, Editorial Síntesis-Fundación ICO. 
SAAVEDRA FAJARDO, D. (1999a) [1640]: Empresas políticas. Edición, anotación y estudio de Sagrario López Poza, Madrid, Cátedra.

SAAVEDRA FAJARDO, D. (1999b) [1640]: Empresas políticas, en López Poza, Sagrario y Sandra $\mathrm{M}^{a}$ Fernández Vales, Catálogo de ediciones digitales de libros de emblemas y obras afines accesibles en Internet /DEBOW (Digital Emblem Books on Web). $5^{a}$ edición. Julio 2013. ISBN:978-84-695-8172-8. (SIELAE http://www.bidiso.es/ sielae/presentacion.htm, Universidade da Coruña - España). http://www.bidiso.es/ emblematica [29/08/13]

SABINE, G. (1980): Historia de la teoría política, México, Fondo de Cultura Económica.

SANTIAGO FERNÁNDEZ, J. (2000): Política monetaria en Castilla durante el siglo XVII, Valladolid, Junta de Castilla y León.

SEGURA ORTEGA, M. (1994): "Pensamiento político en el renacimiento español, Saavedra Fajardo. Ética y política: la razón de Estado", en Vallespín, F (ed.): Historia de la teoría política, II, Alianza Editorial, Madrid, pp. 355-393.

SKINNER, Q. (1992): “Introduction”, en Viroli, M; From politics to reason of state. The acquisition and transformation of the language of politics 1250-1600, Cambridge, Cambridge University Press, pp. 1-10.

SKINNER, Q. (1986): Los fundamentos del pensamiento político moderno: La Reforma, II, México, Fondo de Cultura Económica.

SUREDA CARRIÓN, J.L.(1949): La Hacienda castellana y los economistas del siglo XVII, Instituto de Economía "Sancho de Moncada», número 4 -serie C- Historia de las Doctrinas e Instituciones Económicas, Madrid, Consejo Superior de Investigaciones Científicas.

TOUCHARD, J. (2000). Historia de las ideas políticas, Madrid, Tecnos.

VIROLI, M. (1992): From politics to reason of state. The acquisition and transformation of the language of politics 1250-1600, Cambridge, Cambridge University Press. 